mainly wood-cuts, are taken from old and rare works on the sugar industry, dating back to the eighteenth century, which the author has been able to locate in the course of his researches in various libraries in Great Britain and the United States. There are also many portraits of the famous men of the sugar industry, some of which go back to very early times. Detailed references to literature are given at the end of each chapter, and there is a full index at the end of the second volume.

Although the literature on sugar and sugar cane is now very extensive, the present work constitutes a valuable addition, especially as it deals in so exhaustive a manner with an aspect of the subject which is either omitted or very inadequately covered in most books on sugar.

\section{A SURVEY OF DERMATOLOGY}

Modern Practice in Dermatology

Edited by Dr. G. B. Mitchell-Heggs. Pp. $x x v+836+$ 7 plates. (London: Butterworth and Co. (Publishers), Ltd., 1950.) $63 s$.

THE day of the one-man medical or surgical $I$ text-book seems almost done; it is, perhaps, a pity, but scarcely surprising. What is surprising is the high standard set by such books as the original Osler and Taylor's "Medicine", and in dermatology by the incomparable Darier's "Precis". Nowadays, the medical text-book is a compilation, not only by a number of practising clinicians but also by experts on ancillary subjects, such as zoologists, biochemists and geneticists. This is an obvious advance, although it is inevitable that the authors may express different opinions on the same subject and that the standard of their contributions may not be uniform. The editor of this book, Dr. G. B. Mitchell-Heggs, has on the whole chosen his team well. The majority belong to the younger school, and one feels confident that the future of dermatology in Great Britain is safe in their keeping.

As the editor points out, the book is neither a text-book nor a manual ; and, although some chapters are devoted to single diseases, for example, those dealing with psoriasis, pityriasis rosea and syphilis, in others several dermatoses are considered together. In this latter category are: the distribution of dermatoses, such as disorders of the scalp, hands and feet, and ano-genital region; their causation, for example, diseases due to physical causes, fungus infection and to viruses; and the avitaminoses. The book is not meant to replace the standard manuals for students and general practitioners, or those written primarily for dermatologists, but "is designed to help practitioners, members of the Armed Forces and Government Services, and medical advisers to commercial organisations with international work, throughout the world".

In these days, it is necessary for dermatologists of all countries to study the diseases that are peculiar to or modified by hot climates, and for this reason the three chapters by Dr. L. J. Loewenthal are valuable. They describe the effects of heat and sunlight upon the skin, the peculiarities of the negroskin, cutaneous myasis and onchocerciasis, certain fungus, protozoal, bacterial and virus diseases, the more important avitaminoses, prickly heat and mepacrine dermatitis. These chapters are clearly written and are essentially practical.
Since the monumental work of the late Dr. Prosser White, the importance of industrial diseases of the skin has become increasingly recognized, and, in a brief but authoritative chapter by Dr. Sibyl Horner, preventive measures are rightly stressed and discussed; and in a final paragraph is described the anxiety neurosis which is so often a sequel to indus trial dermatitis and which leads to a superimposed neurodermatitis-c " $\mathrm{He}$ worries and scratches and scratches and worries" puts the problem in a nutshell. The poor state of nutrition, which is mentioned as tending to heighten the susceptibility of the skin to external irritants, might have been discussed more fully, for there is considerable evidence that an excessive intake or diminished tolerance of carbohydrate, particularly sugar, and insufficient protein, favour an eczematous reaction.

Dr. Sibyl Horner's chapter must be read in conjunction with an admirable one on exogenic dermatitis by Dr. F. F. Hellier, who also emphasizes the psychological problem in industrial dermatitis, and with an intriguing one by Dr. David Harley on allergy. The last-named merits very careful study both by dermatologists and general physicians. Of particular interest is the section on bacterial sensitization, focal infection and the toxic focus. Dr. Harley considers that "many cases of so-called food-sensitization dermatoses are due to the effect of the food on an established intestinal infection, leading to increased production of bacterial allergens, which activate a bacterial-sensitization mechanism". In such cases the urticaria or other symptom does not usually develop until eighteen to twenty-four hours after the consumption of the suspected food, in contrast to the shorter period between consumption and onset of symptoms in a true food-sensitization.

$\mathrm{He}$ rightly draws a distinction between a direct toxic effect of bacterial products from some focus of infection, and allergic sensitization to such products. It is common experience that, in certain diseases of the skin and other structures that are clearly due primarily to focal bacterial infection, surgical removal of the focus or foci may be rapidly and completely curative, but has often only a partial or negative effect. The failures are explicable because the majority of the diseases in question are due to allergic hypersensitiveness to bacterial nucleo-proteins or endotoxins, which are not type-specific. Although the main focus or foci may have been removed, diffuse infection of mucous membranes, for example, of the throat or naso-pharynx, with the same or similar strains of organism may persist and supply sufficient allergen for the disease in question to continue. This consideration provides a strong argument in favour of desensitization by vaccine therapy, which, owing to ignorance of technique, has become unpopular. Dr. Harley, it should be noted, strongly supports the pathogen-selective method of Solis-Cohen.

Several other contributions would merit comment and discussion were space available, and, as examples of articles outside the usual range of the text-book, may be mentioned "Animal Diseases Transmissible to Man" by Dr. Sydney Thomson, "Arthropods in Relation to Skin Disease" by Mr. A. Fisk, "Psychosomatic Disorders" by Dr. W. J. O'Donovan, "Diseases of the Skin with Ocular Involvement" by Dr. Alice Carleton, "Biopsy" by Dr. J. H. TwistonDavies, "The Pharmaceutical Aspect" by Mr. M. H. Payne, "Social Aspects of Dermatology" by Dr. M. Feiwel, and a very thoughtful article by the editor on "Cutaneous Manifestations of General Disease". 